\title{
Approche culturelle de l'enseignement du français
}

\section{Françoise Demougin}

\section{(2) OpenEdition}

\section{Journals}

Édition électronique

URL : http://journals.openedition.org/trema/476

DOI : $10.4000 /$ trema.476

ISSN : 2107-0997

\section{Éditeur}

Faculté d'Éducation de l'université de Montpellier

\section{Édition imprimée}

Date de publication : 1 novembre 2008

Pagination : 1-3

ISSN : 1167-315X

\section{Référence électronique}

Françoise Demougin, « Approche culturelle de l'enseignement du français », Tréma [En ligne], 30 |

2008, mis en ligne le 20 septembre 2010, consulté le 10 décembre 2020. URL : http://

journals.openedition.org/trema/476 ; DOI : https://doi.org/10.4000/trema.476

Ce document a été généré automatiquement le 10 décembre 2020.

Trema 


\title{
Approche culturelle de l'enseignement du français
}

\author{
Françoise Demougin
}

1 La question de la culture, à l'heure où certains s'interrogent sur la définition même d'une " culture véritable ${ }^{1}$ ", reste un enjeu majeur de la formation des enseignants et des élèves. Particulièrement en ce qui concerne la didactique des langues - cultures (DLC) qui nous intéresse dans ce numéro. Ce qui distingue, on le sait, la DLC des autres didactiques c'est qu'elle fait de la langue un objet d'enseignement et d'apprentissage et considère en cette dernière l'existence d'une dimension culturelle ${ }^{2}$. L'étude de la culture a donc droit de cité au sein de l'enseignement de la langue ${ }^{3}$, quel que soit le statut de cette dernière : maternelle, étrangère ou seconde, dans la mesure où elle établit un domaine de références hors duquel la production langagière ne fait pas sens, dans la mesure où, notamment, les mots d'une langue renvoient à des significations à l'intérieur d'une culture donnée par et dans une relation sémantique que l'apprenant doit être amené à comprendre4. Cela posé, où en est-on aujourd'hui ? La notion de " langue - culture " a certes permis de reconfigurer la notion de culture dans son appariement avec la langue. Mais cela ne signifie pas qu'elle ne pose plus problème. Au contraire la DLC redevient problématique dans la mesure où la notion même de culture reste à interroger, tout comme la dimension culturelle des apprentissages. Sans doute serait-il plus légitime de distinguer la culture, concept globalisant, des cultures, adaptations de ce concept à des situations didactiques, à des événements linguistiques particuliers. Mais à l'heure où le relativisme culturel d'une part et la mondialisation d'autre part semblent faire vaciller les cultures, comment l'enseignement apprentissage des langues peut-il prendre position?

2 Si la mission de l'école est de faire entrer l'élève dans ce que le sociologue Fernand DUMONT ${ }^{5}$ appelle la « culture seconde ", une forme de culture qui renvoie aux schémas collectifs, à des programmes dont la science, la littérature, l'art, les médias constituent des aspects importants, elle ne peut pour autant ignorer la " culture première » de l'élève, cette forme de culture identifiée par les anthropologues, ancrée dans les processus de socialisation de la vie quotidienne. Car il s'agit là de deux pôles d'un même 
objet, le pôle institutionnalisé et le pôle dispensé, en somme de deux faces solidaires. Or, et c'est là le problème posé à l'école, on sait bien aujourd'hui qu'existe un clivage sinon une rupture entre culture première, celle du quotidien et des usages spontanés, et culture seconde, celle de la mise en forme institutionnelle et symbolique. D'autant que certains voient par ailleurs dans la culture post - moderne de la marchandisation l'apparition d'une culture troisième assignant des valeurs en fonction d'usages marchands. C'est dans cette perspective qu'il nous faut repenser en DLC la question de l'altérité et de ses implications didactiques.

De quoi s'agit-il dans ce numéro ? De proposer une approche culturelle de l'enseignement du français à partir de réflexions portant à la fois sur le degré de pertinence du concept d'interculturalité pour penser les phénomènes de contact entre cultures d'enseignement et cultures d'apprentissage et la place de la culture au sein d'une approche linguistique et anthropologique de l'enseignement - apprentissage d'une langue, en l'occurrence le français.

4 Les articles proposés tentent chacun à leur place d'apporter des réponses ou des pistes de recherche, et de décliner au-delà d'une co-existence culturelle, d'un métissage culturel réel ou fantasmé, une véritable démarche appropriative d'acquisition des langues, et en particulier du français. Des points de résistance apparaissent en effet : comment réduire la discontinuité des apprentissages (dans les classes d'accueil pour Stéphanie CLERC, pour les enfants de migrants pour Martine CHOMENTOWSKI), comment penser l'intérité ${ }^{6}$ et comment trouver un modèle équilibré tant dans l'espace classe (celui des classes bilingues pour Jean DUVERGER) qu'en formation (dans les situations post coloniales pour Soumya EL HARMASSI et Abdellatif BELLAKHDAR), comment retravailler la question de la norme (dans les dictionnaires par la notion de " créolisation » sémique pour Samia KASSAB ; dans les contenus enseignés pour trois contributions qui prônent sous trois angles différents la mise en œuvre d'une didactique contextualisée, intégrée. Pierre DUMONT en demandant : quel français enseigner en Afrique ? et l'on pourrait étendre sa question à la définition même du savoir francophone : quel peut-il être aujourd'hui à l'heure de la mondialisation ? Eric VILLAGORDO ensuite en mettant en avant la diversité culturelle et la dimension expérientielle du rapport à la culture. Françoise DEMOUGIN enfin en analysant l'évolution de la DLC et l'importance des choix méthodologiques à effectuer).

5 Tous ces articles, on le voit, ne peuvent faire l'impasse sur la construction de l'élève comme sujet. Cette construction identitaire pose questions au didacticien : comment éviter que la réaction identitaire, qu'elle soit dans l'acceptation ou le refus de ce qui est proposé, génère de l'échec scolaire ? A quelle(s) expérience(s) de l'altérité peut-on / doit-on confronter l'élève ? Comment prendre en compte la culturalisation des savoirs ? Quelle place et quelle forme réserver à des apprentissages culturels, tels celui de la littérature ou encore de la peinture, dans l'enseignement d'une langue ? L'acuité de ces interrogations empêche les contributeurs de ce numéro d'avoir été tentés par une quelconque esquive. Et il n'est pas, en outre, anodin que des universitaires et des formateurs de différents horizons prennent ici position : FLM, FLE et FLS en effet sont à égalité concernés quand il s'agit, pour reprendre le mot goûteux du poète mauricien Edouard MAUNICK ${ }^{7}$ de faire " malice " avec un français échappé des barrières symboliques du périphérique parisien. Pas plus qu'il n'est anodin que le domaine des sciences échappe à notre numéro : là où les sciences humaines et les arts centrent leur 
démarche de connaissance sur le sujet et construisent sa théorie, les sciences semblent se situer bien davantage dans un discours de savoir qui évacue le sujet ${ }^{8}$.

6 Ce qui apparaît à la lecture de ces articles, outre le renouvellement de la notion d'interculturalité, outre le lien entre la transmission des langues dans et par les cultures et la transmission des cultures dans et par les langues, est en dernier ressort la nécessité, pour installer l'école comme lieu de culture, de penser la question de la culture autrement qu'en termes de contradictions binaires : il faut cesser d'opposer culture anthropologique et culture humaniste, culture maternelle et culture cible, culture linguistique et culture littéraire, et ressaisir dans la culture seconde ce qui s'initie dans la culture première, de la même manière qu'il faut cesser d'opposer savoirs et subjectivité ; il faut réinstaller enfin le sujet dans le langage, dans le langage pris comme objet d'une mémoire collective et d'une expérience individuelle. Le chantier est ouvert, il est loin d'être terminé.

\section{NOTES}

1. On reconnaîtra ici l'expression employée par le Président de la République française le 12 septembre 2008 à Paris dans son discours à l'adresse du Pape Benoît XVI en visite en France.

2. Voir la définition de L. Porcher : « toute langue véhicule avec elle une culture dont elle est à la fois la productrice et le produit. " , in Le Français langue étrangère, émergence et enseignement d'une discipline, CNDP, Hachette Education, Paris, 1995.

3. Avec les avancés en linguistique et en communication, les approches traditionnelles et structuralistes de l'enseignement - apprentissage du FLE en particulier sont délaissées au profit des approches communicatives, tant à l'oral qu'à l'écrit. L'objectif est donc d'être compétent linguistiquement dans les situations à vivre, tout en comprenant les nuances des valeurs pragmatiques des énoncés et en ayant conscience de la variation. C'est dans ce contexte que la notion de langue - culture trouve sa légitimation.

4. Voir à titre seulement d'exemple, l'analyse par M. VERDELHAN-BOURGADE, dans Le Français de scolarisation, pour une didactique réussie, des difficultés posées par la compréhension d'une consigne.

5. Notamment dans son ouvrage Le lieu de l'homme. La culture comme distance et mémoire. Montréal, Éditions HMH (collection Constantes, 14), 1968 ; Montréal, Éditions Fides, (collection du Nénuphar, 67), 1994 ; Bibliothèque québécoise, 1994.

6. On reconnaît là le terme de Rémi HESS dans son ouvrage Pédagogues sans frontière, écrire l'intérité, Paris, Anthropos, 1998, terme retravaillé par Jacques DEMORGON dans sa Critique de l'interculturel, L'horizon de la sociologie, Economica - Anthropos, 2005. L'intérité renvoie, plus que l'interculturalité, à l'enjeu social du « vivre ensemble ».

7. In Actes des Etats généraux des écrivains francophones, Paris, Ministère de la Francophonie, 1989, pp.35-36.

8. Cette opposition est quelque peu forcée ici puisqu'on ne peut occulter par exemple les travaux de BACHELARD sur la formation de l'esprit scientifique... 


\section{AUTEUR}

FRANÇOISE DEMOUGIN

Professeur, Sciences du langage, IUFM de Montpellier - Montpellier 2 Dipralang-Didaxis (EA 739) 